\title{
Cuantificación de los componentes del suelo en secciones delgadas: Mosaicos de alta resolución versus imágenes individuales
}

\author{
Quantification of soil components in thin sections: High resolution mosaics versus \\ individual images
}

\author{
Carlos Alberto Torres-Guerrero' ${ }^{1}$, María del Carmen Gutiérrez-Castorena ${ }^{1, *}$, \\ Edgar Vladimir Gutiérrez-Castorena ${ }^{2}$, Carlos Alberto Ortiz Solorio ${ }^{1}$, Juan Manuel Herrera ${ }^{3}$
}

${ }^{1}$ Programa de Edafología, Colegio de Postgraduados, Campus Montecillo. Km 36.5 Carretera México-Texcoco. 56230 Texcoco, Estado de México, México.

${ }^{2}$ Agua, Suelo y Ciencias Ambientales, Facultad de Agronomía, Universidad Autónoma de Nuevo León, Francisco Villa s/n, Ex-Hacienda "El Canadá", Gral. Escobedo, N.L. 66050, México.

${ }^{3}$ Agroscope, Route de Duillier 50, 1260 Nyon, Suiza.

* Autor para correspondencia: (M.C. Gutiérrez-Castorena) castor@colpos.mx

\section{Gómo citar este artículo:}

Torres-Guerrero, G.A., Gutiérrez-Castorena, M.C., Gutiérrez-Castorena, E.V., Ortiz Solorio, G.A., Herrera, J.M., 2020, Cuantificación de los componentes del suelo en secciones delgadas: Mosaicos de alta resolución versus imágenes individuales: Boletín de la Sociedad Geológica Mexicana 72(1), A300919. http:// dx.doi.org/10.18268/BSGM2020v72n1a300919

Manuscrito recibido: Agosto 22, 2018.

Manuscrito corregido: Diciembre 6, 2018

Manuscrito aceptado: Diciembre 20, 2018.

La revisión por pares es responsabilidad de la Universidad Nacional Autónoma de México.

Este es un artículo Open Access bajo la licencia CC BY-NC-SA (https://creativecommons.org/licenses/by-nc-sa/4.0/)

\section{RESUMEN}

Los cambios en la estructura del suelo se pueden monitorear a partir de muestras inalteradas a través del análisis micromorfométrico de secciones delgadas. En esta metodología es común que se empleen imágenes individuales (de tres hasta diez repeticiones) que no se pueden relacionar en diferentes escalas; además, aunque se establezca un área mínima de estudio, se desconoce su representatividad en los componentes del suelo. El objetivo de este estudio fue cuantificar y los componentes del suelo (poros, agregados y raíces) y comparar los valores obtenidos a partir de imágenes individuales versus mosaicos de alta resolución de toda una sección delgada. Muestras inalteradas fueron colectadas en tres suelos con diferentes contenidos de arcilla (Entisols, Inceptisols y Vertisols) y presencia de raíces de maíz en la misma etapa de desarrollo fenológico (madurez fisiológica). De tres secciones delgadas de cada suelo $\left(4.6 \times 7.2 \mathrm{~cm} \times 30 \mu \mathrm{m} ; 1865 \mathrm{~mm}^{2}\right)$ se obtuvieron imágenes secuenciales de $11.1 \times 7.4 \mathrm{~mm}$ (63 en total) a un aumento de $2 \times$ utilizando un microscopio petrográfico y luz polarizada plana (PPL, por sus siglas en inglés). Los mosaicos de alta resolución espacial $\left(2.6 \mu \mathrm{m}\right.$ píxel $\left.^{-1}\right)$ a una profundidad de color de 24 bits $(8$ bits $\times 3$ bandas en estándar RGB) se construyeron y analizaron utilizando operadores espaciales; posteriormente, se seleccionaron de manera aleatoria tres, cinco y diez imágenes. Tanto las imágenes individuales como los mosaicos fueron transformados mediante componentes principales en $\operatorname{ArcGis}^{\circledR}$ y los constituyentes del suelo fueron delimitados de acuerdo con los valores de sus varianzas. Los resultados indican que las imágenes individuales se recomiendan sólo para cuantificar porosidad o bien en sistemas homogéneos en estructura y color, pero no en sistemas heterogéneos donde los datos obtenidos muestran una alta variabilidad. Incluso cuando los resultados son similares a los calculados en los mosaicos, la dispersión de los datos es alta (varianza 5 veces mayor que la media) y con poca representación. En contraste, con los mosaicos de alta resolución se pueden cuantificar todos los componentes del suelo de toda la sección delgada y se pueden agrupar en clases o categorías para observar las relaciones externas o internas en el sistema del suelo. Además, los componentes del suelo se pueden relacionar con diferentes escalas, por ejemplo, macroagregados y raíces.

Palabras clave: Análisis de imágenes, segmentación, edaforrasgos, análisis de componentes principales, micromorfometría.

\section{ABSTRACT}

Changes in soil structure can be monitored in undisturbed soil samples through the micromorphometric analysis of thin sections. In this methodology, it is common that individual images (three to ten repetitions) are used and that they cannot be related in different scales between soil components; in addition, although a minimum study area is established, its representativeness in the soil components is unknown. The objective of this study was to quantify the soil constituent (pores, aggregates, and roots) and to compare the values obtained from individual images versus high-resolution mosaics from a complete thin section. Unaltered samples were collected in three soils with different clay contents (Entisols, Inceptisols, and Vertisols) and presence of maize roots in the same phenological development stage (physiological maturity). Three thin sections of each soil $(5 \times$ $7 \mathrm{~cm} \times 30 \mu \mathrm{m} 1865 \mathrm{~mm}^{2}$ ) were prepared and sequential images of $11.1 \times 7.4 \mathrm{~mm}$ (63 in total) were obtained at $2 \times$ magnification using a petrographic microscope and plane polarized light (PPL). The high-resolution mosaics (2.6 $\mu \mathrm{m}$ pixel $\left.^{-1}\right)$ at a colour depth 24 bits $(8$ bits $\times 3$ bands in standard $R G B$ ) were built using space operators; subsequently, three, five and ten images were randomly selected. The individual images and the mosaics were transformed by principal component analysis in ArcGis $®$ and soil constituents were delimited according to their variances values. The results indicate that individual images are recommended only to quantify porosity or in homogeneous systems in structure and color, but not in heterogeneous systems where the data obtained show high variability. Even when the results are similar to those calculated in the mosaics, the dispersion of the data is high (variance 5 times greater than the mean) and with little representation. In contrast, high-resolution mosaics offer the total quantification of the thin section and soil components can be grouped into classes or categories to observe intra or inter relations in the soil system. In addition, the soil components can be related to different scales, for example macroaggregates and roots.

Keywords: Image analysis, segmentation, pedofeatures, principal component analysis, micromorphometry. 


\section{Introducción}

La estructura del suelo es uno de los indicadores de calidad más importantes para evaluar la productividad, sustentabilidad y degradación de los ecosistemas naturales o de producción agrícola (agroecosistemas). Para cuantificar los cambios estructurales en el suelo se han incluido un conjunto de datos básicos en donde sobresalen la estabilidad de agregados y la porosidad (Pagliai y Vignozzi, 2002; Allen et al., 2011; Watteau et al., 2019). La estabilidad de agregados se determina por una serie de propiedades químicas, físicas y biológicas, además de su manejo agronómico o prácticas de conservación (Six et al., 2004; Totsche et al., 2017). La porosidad, por su parte, es reconocida como el mejor indicador de la calidad de la estructura del suelo siendo necesaria su cuantificación en términos de forma, tamaño, continuidad, orientación y disposición para definir la complejidad de la estructura y comprender sus modificaciones (Pagliai y Vignozzi, 2002). Además, permite entender la retención y el movimiento del agua en el suelo (Shipitalo y Protz, 1987; Reynolds et al., 2009).

La cuantificación de agregados y poros se ha realizado a través de metodologías convencionales, pero los resultados que se obtienen no son equivalentes entre técnicas y en general tienden a dar mayor importancia a alguno de los mecanismos individuales de desagregación (Gabioud et al., 2011). Una alternativa viable es el análisis micromorfológico de secciones delgadas (Stoops, 2018) en donde se puede incorporar análisis de contexturas, formas, distribución y continuidad, los cuales aportan información detallada de la forma y distribución de poros y agregados del suelo (Gutiérrez y Mejía, 2015; Poch, 2015). La desventaja de este tipo de análisis son los valores de cualquier componente del suelo que se obtienen generalmente a través de imágenes aisladas (Leonard et al., 2019; Poch et al., 2019), las cuales no siempre son representativas a causa de la gran heterogeneidad del suelo (Chesworth, 2008) ya que su área pequeña limita la correlación de los componentes del suelo con diferentes escalas (Zaiets y Poch, 2016). Una solución planteada para reducir el sesgo de representatividad de las microfotografías fue propuesta en la década de los 90's y consistió en el pretratamiento digital (balanceo de color y mejoramiento del contraste) de las imágenes para analizar y cuantificar diferentes componentes del suelo (Protz et al. 1992; Terribile y FitzPatrick, 1992; Protz y VandenBygaart, 1998). Sin embargo, en estas investigaciones nunca hubo consenso en el número de imágenes a analizar debido a las dificultades técnicas y la capacidad de procesamiento de los ordenadores que se usaban en aquel momento.

Otras técnicas son el uso de imágenes de toda la sección delgada obtenidas a través de escáneres, y microtomografias computarizadas. Las primeras dan una idea global de la porosidad, pero son de baja resolución (Bullock y Murphy, 1980; Murphy, 1983; Protz y VandenBygaart, 1998; Jangorzo et al., 2013; Bryk, 2016); mientras que las segundas son una técnica no invasiva y se usan para evaluar la estructura (Lebedeva et al., 2019), porosidad del suelo (Turk y Graham, 2014; Kumi et al., 2015; Stoops, 2015) y su distribución espacial en dos y tres dimensiones (Pires et al., 2011; Carducci et al., 2017; Lebedeva et al., 2019). Sin embargo, las microtomografias computarizadas son deficientes para interrelacionar a los componentes dentro de la matriz órgano-mineral del suelo (Taina et al., 2008).

Los mosaicos de alta resolución $(0.0026 \mathrm{~mm}$ píxel $\left.^{-1}\right)$ pueden ser una alternativa pues resuelven varios de estos inconvenientes al: i) cubrir la totalidad de la sección delgada (Gutiérrez-Castorena et al., 2018; Sauzet et al., 2017), ii) cumplir con el concepto de área mínima representable (REA por sus siglas en inglés) propuesto por VandenBygaart y Protz (1999) y poder relacionar cualquier componente del suelo con altos porcentajes de precisión (Gutiérrez-Castorena et al., 2018). Más aún, con el procesamiento digital de imágenes (Protz et al., 1992; Protz y VandenBygaart, 1998) es posible obtener la varianza de los componentes del suelo en dos formas: i) en imágenes individuales 
(Pineda-Marín et al., 2012) y ii) comparando los valores obtenidos con la totalidad de la sección delgada a partir de mosaicos de alta resolución (Gutiérrez-Castorena et al., 2018). De esa manera se pueden estandarizar los protocolos antes de comparar los valores de porosidad (Marcelino et al., 2007).

El objetivo de esta investigación fue cuantificar los componentes del suelo (poros, agregados y raíces) y comparar los valores obtenidos a partir de mosaicos de alta resolución versus imágenes individuales tomadas de manera aleatoria (tres, cinco y diez) de toda la sección delgada del suelo, para determinar su representatividad en condiciones homogéneas / heterogéneas del suelo.

\section{Materiales y métodos}

\subsection{SELEGGIÓN DE MUESTRAS}

Tres suelos de uso agrícola con diferentes cantidades de arcilla fueron seleccionados para colectar muestras inalteradas con ayuda de cajas tipo Kubiena. Dos suelos provienen del estado de Hidalgo: Vertisols (Udic Haplausterts) e Inceptisols (Typic Dystrustepts), según el levantamiento etnoedafológico realizado por Torres-Guerrero et al. (2019). Un suelo más provino del campo experimental del Colegio de Postgraduados campus Montecillo, Estado de México: Entisol (Typic Ustifluvents) (González, 2008). Las muestras inalteradas se tomaron a 55 días después de la siembra cerca de plantas de maíz, a $10 \mathrm{~cm}$ de la zona de influencia radical y a $10 \mathrm{~cm}$ de profundidad para asegurar raíces dentro de las cajas. En todos los suelos se colectaron tres muestras cerca de la misma planta para que éstas pudieran fungir como repeticiones de las cuantificaciones.

\subsection{ELABORAGIÓN DE SEGGIONES DELGADAS}

Las muestras colectadas fueron secadas al aire y a la sombra para su posterior impregnación con resina poliéster y monoestireno en una relación
3:1. La elaboración de las secciones delgadas de suelo $(5 \times 7 \mathrm{~cm} \times 30 \mu \mathrm{m})$ se llevó a cabo de acuerdo con Murphy (1986) y los componentes del suelo (porosidad, agregados, raíces) se describieron utilizando la terminología propuesta por Bullock et al. (1985) y Stoops (2003).

\subsection{ADQUISICIÓN DE IMÁGENES}

En cada sección delgada se tomaron 63 imágenes de manera secuencial utilizando una cámara digital Canon Rebel T3i (12.2 Megapixeles), acoplada a un microscopio petrográfico Olympus BX51. El objetivo utilizado fue $2 \times$ con sólo una fuente de luz (luz polarizada plana, PPL). Cada imagen $(11.1 \times$ $7.4 \mathrm{~mm}$ ) fue capturada en el formato original de la cámara *.CR2 y transformada a formato *.TIFF. La resolución de cada imagen fue de $4290 \times 2856$ píxeles; $0.0026 \mathrm{~mm}$ píxel $^{-1}$ y una profundidad de color de 24 bits (8 bits $\times 3$ bandas en estándar: roja, verde y azul; RGB por sus siglas en inglés).

\subsection{ELABORAGIÓN DE LOS MOSAICOS}

Los mosaicos de alta resolución se construyeron utilizando operadores espaciales de acuerdo con la técnica propuesta por Gutiérrez-Castorena et al. (2016; 2018). Cada mosaico se integró inicialmente de 56 a 63 imágenes; no obstante, los mosaicos fueron recortados a un área total de 1865 mm² (6×5 imágenes aproximadamente; 367, 567, 200 píxeles $\mu^{2}{ }^{2}$ ) para evitar subestimaciones por el efecto de borde y adelgazamiento del pulido de las secciones delgadas.

\subsection{ANÁLISIS DIGITAL DE IMÁGENES}

\subsubsection{IMÁGENES AISLADAS}

De las imágenes secuenciales tomadas para los mosaicos se eligieron de forma aleatoria tres, cinco y diez por tratamiento dentro de cada sección delgada. Además, no se usaron imágenes subsecuentes para evitar las zonas de traslapes que fueron empleadas para la construcción del mosaico. Las imágenes fueron sometidas a un 
proceso de transformación de tres bandas (RGB), con una profundidad de color de 24 bits, a imágenes en escala de grises (binarias de 8 bits) con ayuda del software Fiji de ImageJ (Schindelin et al., 2012) para su posterior análisis. A cada una de las imágenes binarizadas se le practicó una segmentación a través del comando ISO cluster unsupervised dentro del software ArcGis 10.3®, dando como resultado una capa raster de categorías divididas con base en sus valores de saturación de grises. Con la ayuda de la imagen original, las categorías fueron reclasificadas en tres capas raster: espacio poroso, agregados y raíces. Posteriormente, las imágenes fueron vectorizadas para cuantificar sus áreas (polígonos) (Figura 1).

\subsubsection{MOSAICOS DE ALTA RESOLUCIÓN}

La delimitación y cuantificación de los componentes del suelo se llevó a cabo utilizando ArcGis ${ }^{\circledR}$ 10.3 (Environmental Systems Research Institute, 2015). Para reducir la información y optimizar el procesamiento de los mosaicos en un ordenador convencional, se realizó un pretratamiento a las imágenes que consistió en la transformación de componentes principales integrados por tres capas a una sola capa o componente (el cual representa más del 97\% de la información de la imagen original) y de esta manera se redujo el tamaño de la imagen de Gigabytes a Megabytes. Además, se eliminaron los cálculos redundantes debido a la composición de múltiples imágenes de los mosaicos (Terribile y FitzPatrick, 1992; Campbell, 1996). Al finalizar el pretratamiento de las imágenes, con la capa resultante de cada mosaico de obtuvieron las varianzas representativas de cada componente del suelo en escala de grises.

Posteriormente, se realizó una clasificación no supervisada (ISO cluster unsupervised) con 30 categorías y posteriormente, una reclasificación por atributos con la ayuda de la imagen original (color verdadero) más la del componente principal (generando falsos colores para cada componente del suelo) y la imagen resultante de la clasificación no supervisada. Con este proceso se delimitaron los agregados, raíces y espacio poroso en capas raster, que posteriormente fueron vectorizadas para su cuantificación final.

En el caso de los agregados, los vectores resultantes de cada mosaico se utilizaron para cuantificar y dividir los agregados en cinco clases: I) microagregados (<250 $\mu \mathrm{m}$ o 8180 píxeles), II) macroagregados muy finos $(250-500 \mu \mathrm{m} \mathrm{o}$ 8180-29254 píxeles), III) finos (500-1000 $\mu$ m о 29254-117164 píxeles), IV) medios (1000-5000 $\mu \mathrm{m}$ o 117164-3272000 píxeles) y V) gruesos (>5000 um o 3272000 píxeles) utilizando la propuesta de Gutiérrez-Castorena et al. (2018).

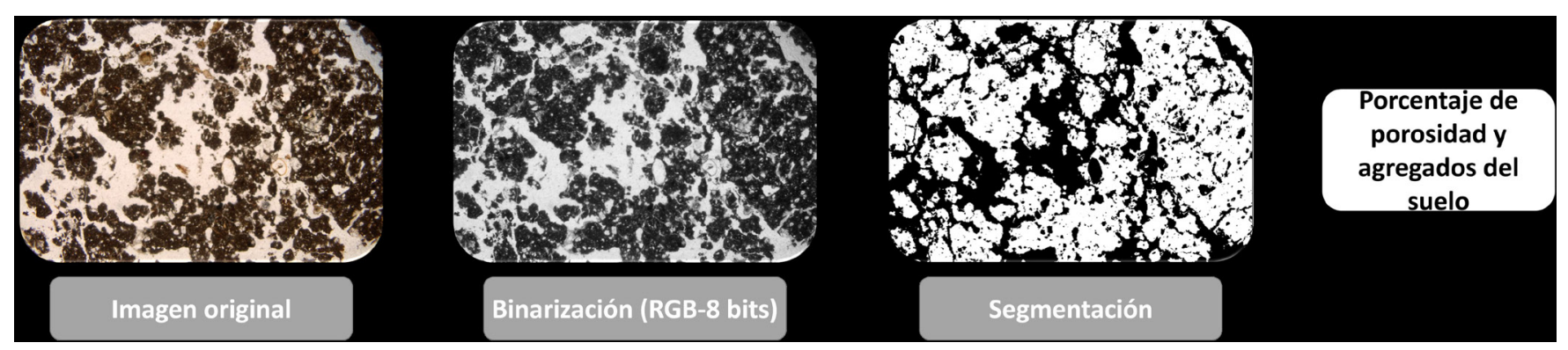

Figura 1 Proceso para la cuantificación del porcentaje de espacio poroso y agregados del suelo en imágenes aisladas de las secciones delgadas a una magnificación de $2 \times$. 


\section{Resultados}

Los contenidos de arcilla y algunas propiedades fueron obtenidas de los levantamientos edafológicos realizados por González (2008) y Torres-Guerrero et al. (2019) y son mostrados en la Tabla 1.

\subsection{POROSIDAD}

La porosidad calculada en la totalidad de los mosaicos varió de $42 \%$ a $55 \%$ en los tres suelos y en todos los casos la variación entre repeticiones no superó el 5\%, con valores de 40-43\% en Entisols, $51-55 \%$ en Inceptisols y $50 \%-55 \%$ para Vertisols (Tabla 2). Cuando se contrastaron los resultados obtenidos mediante imágenes individuales, la variación entre repeticiones fue mayor en todos los casos $(9 \%, 11 \%$ y $16 \%$ para Inceptisols, Entisols y Vertisols, respectivamente).

En cuanto a los valores promediados de las repeticiones empleando la técnica convencional se puede observar que al usar tres imágenes se obtienen los valores más cercanos a la media calculada en los mosaicos de los tres suelos. En el $70 \%$ de los casos en donde se empleó la cuantificación con imágenes individuales, la varianza resultó ser mayor (hasta $300 \%$ ) que la media calculada.

$\mathrm{Al}$ aumentar de 3 a 10 imágenes se puede reducir la varianza: Inceptisols (de 125 a 69) y Vertisols (de 70 a 53) pero no en Entisols, en donde se tienen valores con un comportamiento irregular (véase Tabla 2).

\subsection{AGREGADOS Y RAÍCES}

El tipo de agregados predominante en cada suelo fue el siguiente: en Entisols se presentan agregados del tipo migajoso y granular en proporciones similares; en Inceptisols los bloques subangulares dominan por encima de los migajosos y granulares; por último, en Vertisols se observó un mayor número de agregados migajosos seguido por bloques subangulares (Figura 2).

La cuantificación de los agregados en cada una de las repeticiones donde se usaron fotografías individuales presentó una gran dispersión de los datos con valores por encima de la media al igual que los obtenidos en la porosidad. La mayor variación se registró cuando se emplearon tres imágenes en Entisols (11\%) e Inceptisols (9\%), y cinco y diez imágenes en Vertisols (25\%) como se puede observar en la Figura 3a, 3b y 3c. En cuanto a los valores promedio calculados en todos los tratamientos, la mayor varianza $\left(\sigma^{2}\right)$ se alcanzó en Entisols (128.94), seguido de Inceptisols (81.38) y Vertisols (92.21). Por otro lado, la variación de los valores obtenidos en los mosaicos para Entisols e Inceptisols no superó el 10\%; mientras que para Vertisols fue de 18\% (Figura 3d). Además, la cuantificación de agregados por medio de vectores en los mosaicos de alta resolución permitió clasificar a los agregados en diferentes categorías según su diámetro en una categoría de microagregados $(<$ $250 \mu \mathrm{m}$ ) y cuatro de macroagregados (250 y hasta $>5000 \mu \mathrm{m})$. En este sentido es posible observar que sólo en Vertisols existe una distribución uniforme de todas las clases de agregados; mientras que en Entisols e Inceptisols ocurre una mayor proporción de macroagregados clases IV y $\mathrm{V}$ (Tabla 3).La separación en clases de diferentes tamaños de agregados permitió no sólo observar distribución y dominancia de cada categoría, sino

Tabla 1. Propiedades edáficas en donde se obtuvieron las muestras para elaborar las secciones delgadas de suelo.

\begin{tabular}{|c|c|c|c|c|}
\hline Suelo & $\begin{array}{c}\text { Cantidad de } \\
\text { arcilla }\end{array}$ & Clase Textural & $\begin{array}{c}\text { Densidad } \\
\text { Aparente } \\
\left(\mathbf{g ~ c m}^{-3}\right)\end{array}$ & $\begin{array}{c}\text { M.O. } \\
(\%)\end{array}$ \\
\hline Typic Ustifluvents (Entisols) & 37 & Franco-arcilla-limosa & 1.3 & 2.08 \\
\hline Typic Dystrustepts (Inceptisols) & 43 & Arcillosa & 1.43 & 1.16 \\
\hline Udic Haplusterts (Vertisols) & 57 & Arcillosa & 1.52 & 4.25 \\
\hline
\end{tabular}


también la relación con la porosidad del suelo. En la Figura 4 se muestra como ejemplo, uno de los mosaicos de Vertisols en el cual es fácil reconocer las clases de agregados e inferir acerca del tipo y la magnitud de los poros que se generan.Los valores promedio de raíces obtenidos en la totalidad de las secciones delgadas para los tres suelos difirió entre imágenes individuales y mosaicos con $4.54 \%$, $2.66 \%$ y $0.63 \%$ para los Vertisols, Entisols e Inceptisols, respectivamente (Tabla 4). En la Figura 5 se puede apreciar que cuando se usan únicamente tres imágenes existe una gran variabilidad en la distribución de poros y agregados del suelo y una escasa presencia de raíces provocando diferencias abruptas entre la cuantificación de imágenes. Cuando se emplearon cinco imágenes, la variabilidad entre poros y agregados se redujo (hasta en $10 \%$ ), pero si se agrega un componente tan heterogéneo en su distribución como son las raíces, las diferencias se incrementan $>20 \%$ (Figura 6).

Con diez imágenes la variación disminuye, aunque los datos de varianza son altos; por ejemplo, en agregados se pueden obtener valores desde $22.51 \%$ hasta $49.38 \%$ (Figura 7 ).

Tabla 2. Porosidad del suelo calculado con técnicas convencionales (imágenes aisladas) y mosaicos de alta resolución compuestos de imágenes secuenciales en los tres suelos muestreados.
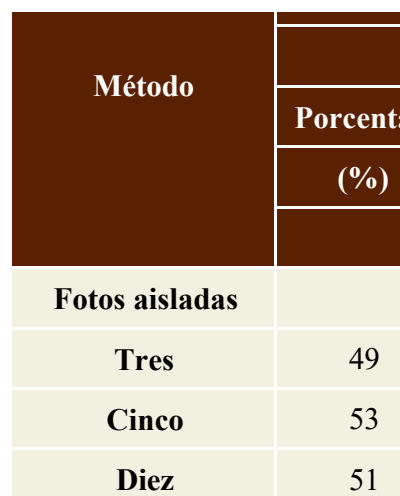

Mosaico

43

\begin{tabular}{|c|c|}
\hline 66.91 & 38 \\
\hline 149.82 & 45 \\
\hline 87.98 & 40 \\
\hline
\end{tabular}

38
45
40

40

60.37
280.56
114.7

Inceptisols (Typic Dystrustepts)

Fotos aisladas

\begin{tabular}{|c|c|c|c|c|c|c|c|c|}
\hline Tres & 53 & $17.31^{\dagger}$ & 49 & 125.44 & 53 & $49.42^{\dagger}$ & 52 & 125.44 \\
\hline Cinco & 51 & $26.01^{\dagger}$ & 49 & 117.29 & 53 & $47.06^{\dagger}$ & 51 & 117.29 \\
\hline Diez & 52 & 50.69 & 41 & 65.77 & 44 & 92.16 & 46 & 69.54 \\
\hline Mosaico & 55 & & 51 & & 52 & & 53 & \\
\hline
\end{tabular}

Vertisols (Udic Haplusterts)

\section{Fotos aisladas}

\begin{tabular}{|c|c|c|c|c|c|c|c|c|}
\hline Tres & 55 & $8.35^{\dagger}$ & 59 & 70.73 & 47 & $25.91^{\dagger}$ & 54 & 70.73 \\
\hline Cinco & 41 & $5.90^{\dagger}$ & 57 & 58.68 & 45 & $48.16^{\dagger}$ & 48 & 58.68 \\
\hline Diez & 50 & 53.58 & 45 & $13.12^{\dagger}$ & 39 & $25.60^{\dagger}$ & 45 & 53.58 \\
\hline Mosaico & 55 & & 50 & & 53 & & 53 \\
\hline
\end{tabular}




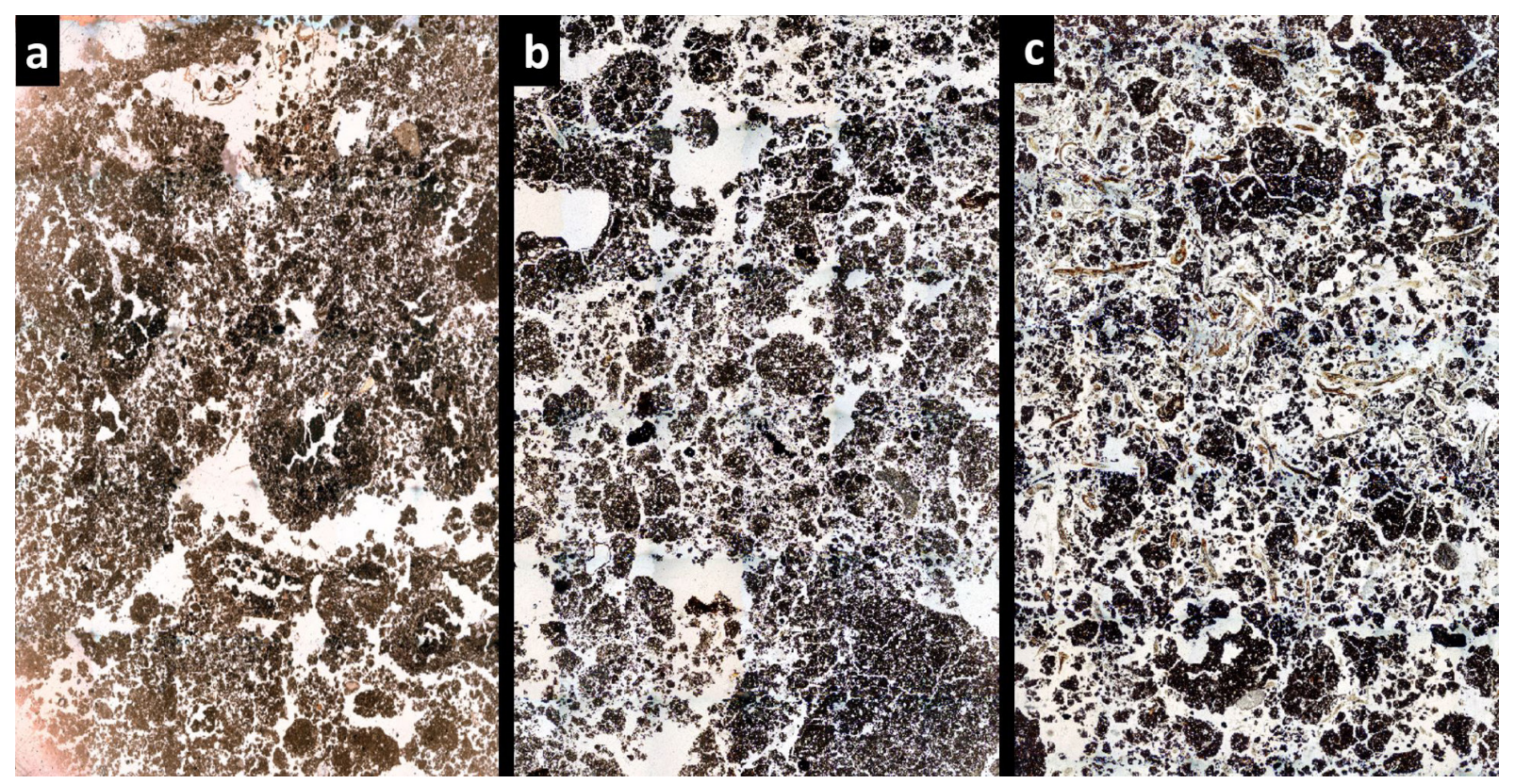

Figura 2 Proceso para la cuantificación del porcentaje de espacio poroso y agregados del suelo en imágenes aisladas de las secciones delgadas a una magnificación de $2 \times$.

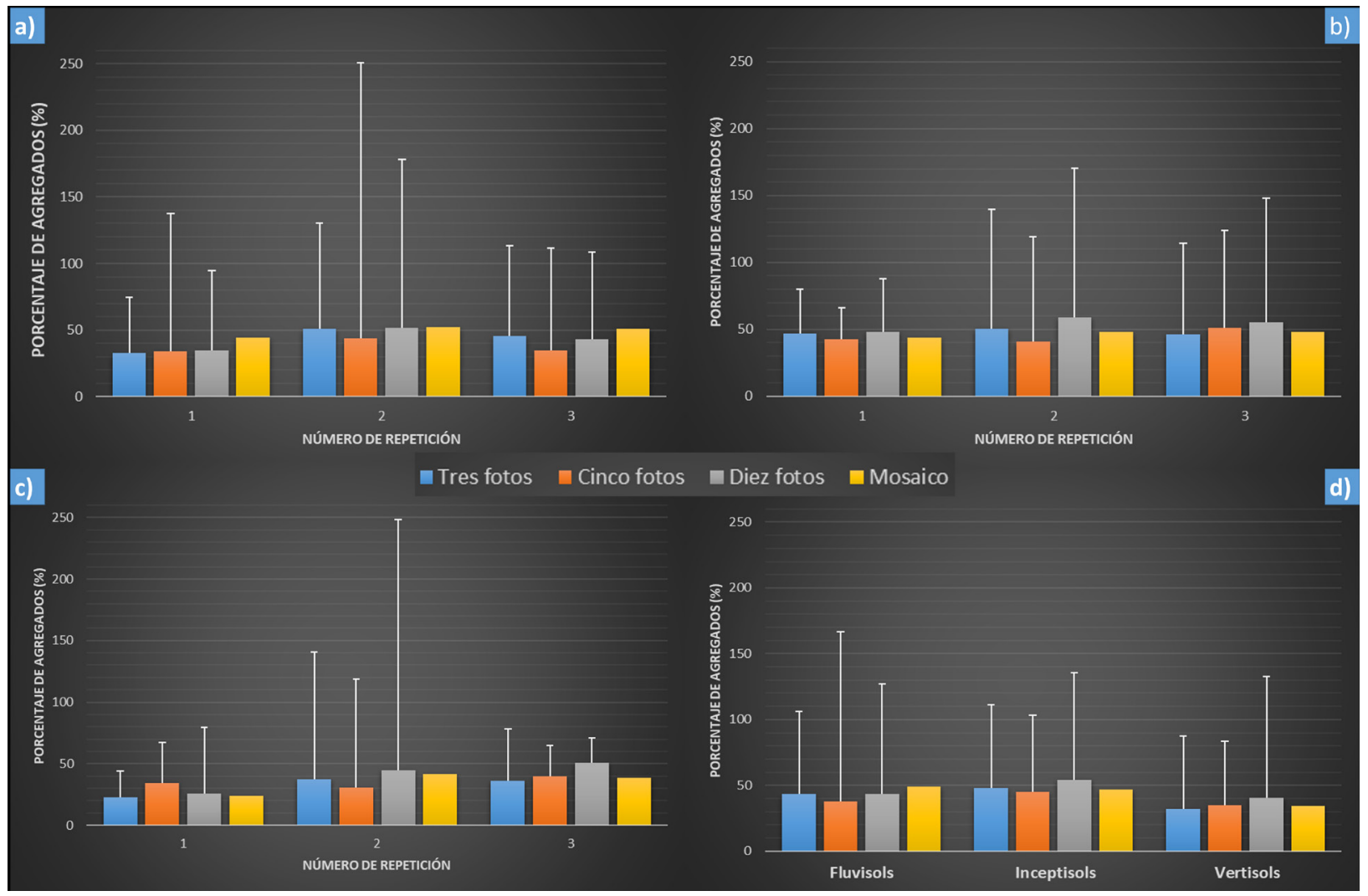

Figura 3 Porcentaje de agregados calculados en fotografías aisladas versus mosaicos de alta resolución de secciones delgadas en a) Entisols, b) Inceptisols, c) Vertisols y d) el valor promedio obtenido de las repeticiones. 


\subsection{TIEMPO DE ANÁLISIS}

El tiempo que toma cada método de análisis para obtener el resultado final, es decir, la cuantificación de cada componente del suelo se reporta en la Tabla 5. Un mayor número de imágenes puede reducir la dispersión y por consecuencia la varianza de los datos de las cuantificaciones en agregados y poros. Por ejemplo, en un análisis de 20 o 30 imágenes individuales será necesario entre 120 y 150 minutos comparados con los 170 minutos que se requieren en un mosaico de 49 imágenes.

Tabla 3. Distribución de los agregados cuantificados en los mosaicos de alta resolución y clasificados en diferentes clases de tamaño. Clase I) microagregados (< $250 \mu \mathrm{m})$, clase II) macroagregados muy finos $(250-500 \mu \mathrm{m})$, clase III) finos (500$1000 \mu \mathrm{m})$, clase IV) medios (1000-5000 $\mu \mathrm{m})$ y clase V) gruesos $(>5000 \mu \mathrm{m})$.

\begin{tabular}{|c|c|c|c|c|}
\hline \multirow{4}{*}{ Clase } & \multicolumn{4}{|c|}{ Porcentaje de agregados (\%) } \\
\hline & \multicolumn{3}{|c|}{ Número de repetición } & \multirow{2}{*}{ Promedio } \\
\hline & 1 & 2 & 3 & \\
\hline & \multicolumn{4}{|c|}{ Entisols (Typic Ustifluvents) } \\
\hline I & 3.25 & 4.78 & 2.54 & 3.52 \\
\hline II & 2.01 & 2.67 & 1.89 & 2.19 \\
\hline III & 6 & 6.05 & 2.43 & 4.83 \\
\hline IV & 13.04 & 13.23 & 18.47 & 14.91 \\
\hline $\mathbf{V}$ & 20.2 & 25.45 & 25.84 & 23.83 \\
\hline \multirow[t]{2}{*}{ Total } & 44.5 & 52.18 & 51.17 & 49.28 \\
\hline & \multicolumn{4}{|c|}{ Inceptisols (Typic Dystrustepts) } \\
\hline I & 4 & 4.4 & 2.81 & 3.74 \\
\hline II & 2.04 & 1.59 & 1.05 & 1.56 \\
\hline III & 4.55 & 2.6 & 2.26 & 3.14 \\
\hline IV & 16.4 & 7.68 & 8.85 & 10.98 \\
\hline $\mathbf{V}$ & 16.81 & 31.88 & 32.91 & 27.2 \\
\hline \multirow[t]{2}{*}{ Total } & 43.8 & 48.15 & 47.88 & 46.61 \\
\hline & \multicolumn{4}{|c|}{ Vertisols (Udic Haplusterts) } \\
\hline I & 8.11 & 4.33 & 5.22 & 5.89 \\
\hline II & 3.49 & 1.71 & 2 & 2.4 \\
\hline III & 6.39 & 2.31 & 3.03 & 3.91 \\
\hline IV & 5.85 & 3 & 7.7 & 5.52 \\
\hline V & 0 & 30.02 & 20.49 & 16.84 \\
\hline Total & 23.84 & 41.37 & 38.44 & 34.55 \\
\hline
\end{tabular}

\section{Discusión}

\subsection{IMÁGENES INDIVIDUALES}

El análisis de imágenes aisladas resulta ser una de las técnicas más empleadas para la cuantificación de componentes del suelo en secciones delgadas, debido a su practicidad y bajo costo de implementación; no obstante, se debe considerar la homogeneidad/heterogeneidad del suelo (Bullock et al., 1985). Para cuantificar la porosidad en suelos homogéneos (Inceptisols y Vertisols) con dominancia de un solo tipo de poros (fisuras), son suficientes tres fotografías para obtener variaciones entre muestras menores a 10\%, lo que concuerda con los resultados obtenidos por Ringrose Voase (1996) y Poch et al. (2019). De hecho, Pineda-Marín et al. (2012) encontraron que en sustratos con poros de empaquetamiento simple o compuesto se puede obtener una desviación estándar por debajo de $10 \%$, con alta aproximación de los valores reales de la totalidad de una sección delgada. En contraste, cuando el suelo es heterogéneo con dominancia de más de un tipo de poros (como en Entisols; Figura 2) a causa de una mayor actividad biológica (Zaiets y Poch, 2016), la variabilidad se incrementa $(>10 \%)$ y los datos son estadísticamente no confiables.

Las imágenes individuales también son útiles cuando los agregados tienen un patrón de distribución homogéneo en términos de color y tipo de agregados como es el caso de los Entisols e Inceptisols estudiados. No obstante, en un sistema heterogéneo de agregados no sólo en el tipo (migajosos y bloques subangulares), sino también en el tamaño, se pueden obtener valores que los sobre o subestime hasta en más de $25 \%$, como es el caso de los Vertisols. En estos suelos, la cuantificación de los agregados y su porosidad es muy importante para monitorear todo el manejo agronómico (Coulombe et al.,1996; Chesworth, 2008; Torres-Guerrero, 2016).

En cuanto al REA para evaluar porosidad y agregados, las imágenes individuales cumplen con lo establecido por VandenBygaart y Protz (1999); sin embargo, sus varianzas son muy altas (> 200), 

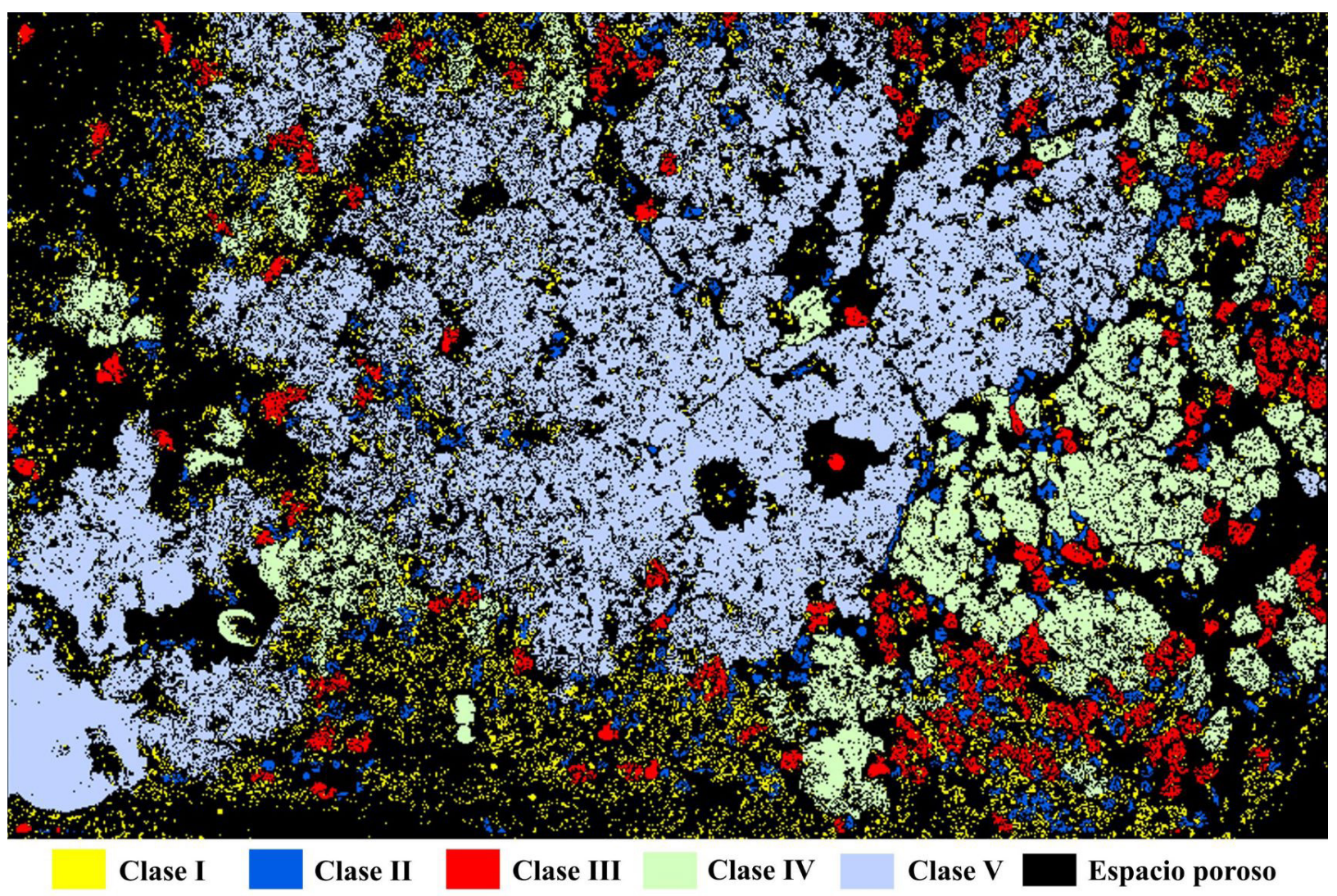

Figura 4 Distribución por clases de agregados en un mosaico de alta resolución correspondiente al tratamiento de Vertisols y rotación de cultivo en el mes octubre. La estructura del suelo puede ser visualizada y correlacionada con otros componentes del suelo en la totalidad de la sección delgada. Longitud del marco $54.17 \mathrm{~mm}$. Clase I microagregados (<250 $\mu \mathrm{m})$, clase II) macroagregados muy finos $(250-500 \mu \mathrm{m})$, clase III) finos (500-1000 $\mu \mathrm{m})$, clase IV) medios $(1000-5000 \mu \mathrm{m})$ y V) gruesos $(>5000 \mu \mathrm{m})$.

ya que en algunos casos los agregados $>5000$ $\mathrm{mm}$ ) ocupaban $>70 \%$ de una imagen causando un problema de representatividad. Asimismo, al incorporar un componente más (en este caso las raíces) a la delimitación y cuantificación, los valores de imágenes aisladas distaron considerablemente de la cuantificación total, ya que el patrón de distribución de las raíces se encuentra relacionado con el tipo de agregados (migajosos) y poros (de empaquetamiento compuesto) del suelo, haciendo poco confiable esta técnica debido a que la varianza que se registró fue hasta 5 veces mayor a la media.

\subsection{MOSAICOS DE ALTA RESOLUGIÓN}

La heterogeneidad del suelo se analiza más eficientemente con mosaicos debido a que la variabilidad se reduce significativamente $(<5 \%)$ y se resuelven las sobrestimaciones de las imágenes aisladas (Aydemir et al., 2004). Además, se pueden cuantificar y relacionar todos los componentes del suelo (Gutiérrez-Castorena et al., 2018), algo que no se alcanza con la microtomografía computarizada (Stoops, 2018). Guando se presentan agregados $>$ 8000 mm comunes en los Vertisols (Bravo-Garza y Bryan, 2005), se recomienda usar la segmentación y algoritmos para clasificar a los agregados en diferentes tamaños.

Con el procesamiento digital de imágenes complejas, los resultados pueden ser uniformizados y reproducidos por cualquier usuario (Marcelino et al., 2007), pero conservando la heterogeneidad del suelo para reconocer mayor detalle de ciertos componentes y área observada (FitzPatrick, 1984; Stoops, 2003). Por ejemplo, se puede seleccionar 
uno o más constituyentes (raíces y agregados) y determinar su distribución y relación en el desarrollo estructural de un suelo (Fitzpatrick, 1990; Stoops, 2003).

En estudios anteriores, las relaciones entre raíces con la microestructura (Moran, 1993; Moran et al., 2000), con la porosidad (Kodešová et al., 2006) o con la formación de agregados del suelo (De León-González et al., 2007) se llevaban a cabo en áreas muy pequeñas o con imágenes de baja resolución. Entonces, si la finalidad de los estudios es demostrar diferentes procesos, relaciones o distribuciones de edaforrasgos dentro de una sección delgada, el uso de mosaicos de alta resolución es una alternativa más eficiente (Gutiérrez-Castorena et al., 2018). Además, se pueden trabajar múltiples escalas microscópicas en una computadora y aplicar el concepto de homogeneidad/heterogeneidad (Bullock et al., 1985). De hecho, la tendencia hacia el futuro es incorporar dos o más análisis en donde se integren múltiples escalas para correlacionar los análisis físicos y químicos del laboratorio con la actividad biológica y los procesos de pedogénesis (Jangorzo et al., 2013, Carducci et al., 2017).

Con esta metodología también es posible implementar análisis cuantitativos que comprendan uno o varios componentes del suelo a diferencia de la microtomografía computarizada, la cual es deficiente al delimitar componentes del suelo dentro de la matriz órgano-mineral y los procesos biológicos

Tabla 4. Distribución de raíces en el suelo calculado con técnicas convencionales (imágenes aisladas) y mosaicos de alta resolución compuestos de imágenes secuenciales en los tres suelos muestreados.

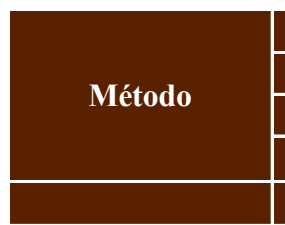

\begin{tabular}{|c|c|}
\hline \multicolumn{2}{|c|}{1} \\
\hline Porcentaje & Varianza \\
\hline$(\%)$ & $\left(\sigma^{2}\right)$ \\
\hline
\end{tabular}

Número de repetición

\begin{tabular}{|c|c|}
\hline 2 & 3 \\
\hline
\end{tabular}

Fotos aisladas

\begin{tabular}{|c|c|c|c|c|c|c|c|c|}
\hline Tres & 17.91 & 51.64 & 10.86 & 71.57 & 5.43 & 9.73 & 11.4 & 44.31 \\
\hline Cinco & 12.75 & $4.60^{\dagger}$ & 11.25 & 51.98 & 11.14 & 30.08 & 11.71 & 29.13 \\
\hline Diez & 14.12 & 21.87 & 8.48 & 47.61 & 9.78 & 13.84 & 10.79 & 27.77 \\
\hline Mosaico & 12.5 & & 7.82 & & 6.83 & 12.5 & 9.05 & \\
\hline
\end{tabular}

Inceptisols (Typic Dystrustepts)

Fotos aisladas

\begin{tabular}{|c|c|c|c|c|c|c|c|c|}
\hline Tres & 0.09 & $0.07^{\dagger}$ & 0.27 & $0.14^{\dagger}$ & 0.71 & $0.15^{\dagger}$ & 0.36 & $0.12^{\dagger}$ \\
\hline Cinco & 0.09 & $0.05^{\dagger}$ & 0.26 & $0.10^{\dagger}$ & 0.84 & $0.38^{\dagger}$ & 0.4 & $0.18^{\dagger}$ \\
\hline Diez & 0.08 & $0.05^{\dagger}$ & 0.26 & $0.11^{\dagger}$ & 0.75 & $0.26^{\dagger}$ & 0.36 & $0.14^{\dagger}$ \\
\hline Mosaico & 1.11 & & 0.95 & & 0.29 & & 0.78 \\
\hline
\end{tabular}

Vertisols (Udic Haplusterts)

Fotos aisladas

\begin{tabular}{|c|c|c|c|c|c|c|c|c|}
\hline Tres & 26.63 & $4.00^{\dagger}$ & 13.37 & 29.16 & 10.94 & 32.38 & 16.98 & 21.85 \\
\hline Cinco & 24.63 & $5.86^{\dagger}$ & 12.46 & 30.47 & 10.03 & 28.03 & 15.71 & 21.45 \\
\hline Diez & 24.02 & $4.54^{\dagger}$ & 10.05 & 35.65 & 10.01 & 25.3 & 14.69 \\
\hline Mosaico & 21.12 & & 8.1 & & 8.1 & & 12.44 \\
\hline
\end{tabular}

†Tratamientos en los que la varianza resultó menor a la media. 


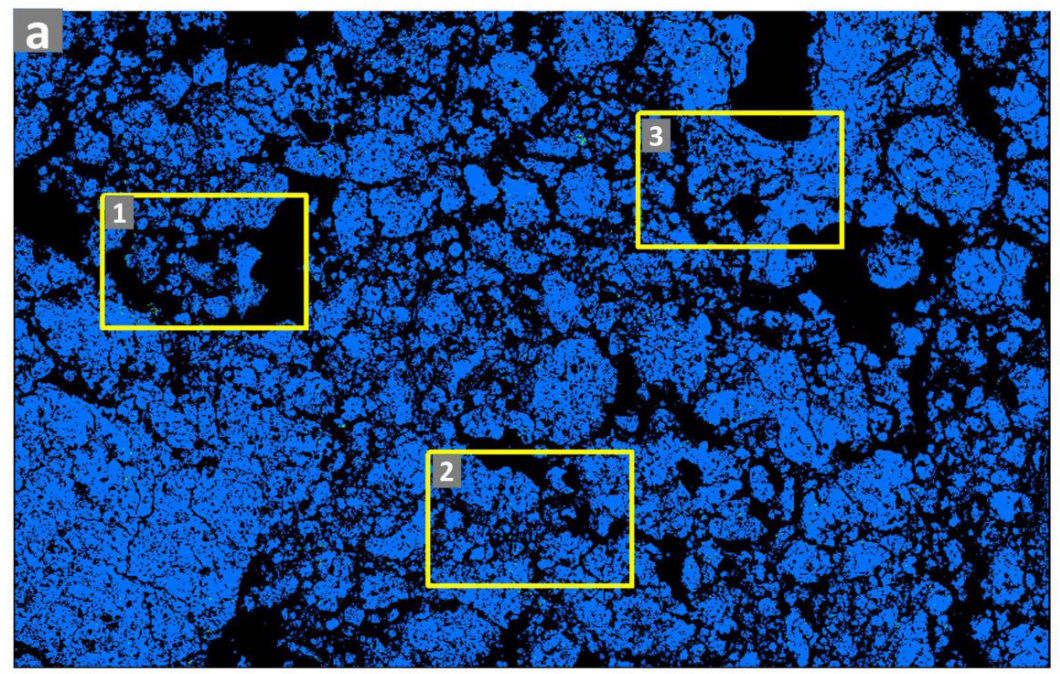

$A=53.4 \% \quad R=0.15 \quad P=46.44 \%$

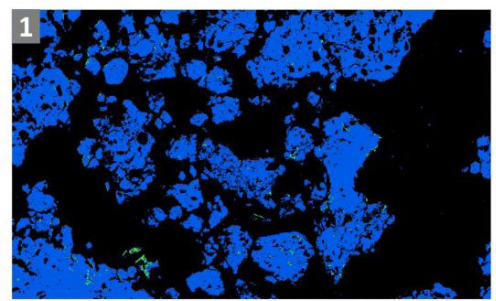

$A=48.06 \% \quad R=0.25 \quad P=51.68 \%$

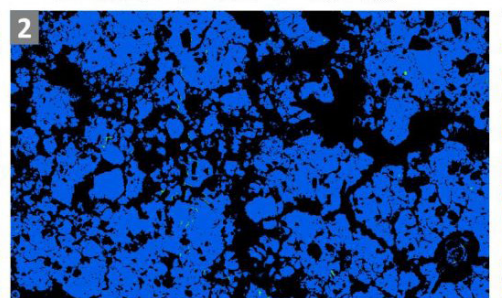

$\mathrm{A}=\mathbf{5 8 . 7 4 \%} \mathrm{R}=\mathbf{0 . 1 1} \mathrm{P}=\mathbf{4 1 . 1 4} \%$

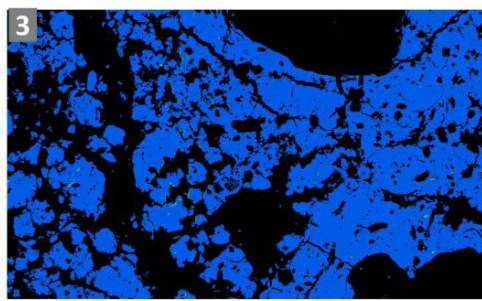

$A=53.40 \% \quad R=0.09 \quad P=46.50 \%$

Raíces (R) Agregados (A) $\square$ Espacio poroso (P)

Figura 5 Cuantificación de los componentes del suelo en el mosaico de alta resolución (a) y en tres imágenes aisladas en Inceptisols en el mes de agosto. Longitud del mosaico (a) $54.17 \mathrm{~mm}$ y de las fotografías aisladas (1 a 3) $8.32 \mathrm{~mm}$.

que ocurren en el suelo (Taina et al., 2008). Los mosaicos proporcionan un medio de descripción e interpretación adicional a los estudios convencionales, al correlacionar espacialmente dichos rasgos en áreas completas de secciones delgadas (Adderley et al., 2002). Además, se pueden interrelacionar elementos que no siempre coinciden en escala como es el caso de las bacterias con los agregados del suelo y los componentes minerales (Nunan et al., 2003; Gutiérrez-Castorena et al., 2016) o los revestimientos arcillosos con la macro y microporosidad (Sauzet et al., 2017).

Finalmente, en cuanto a la pedogénesis, en esta investigación se demostró que la prevalencia de raíces en Vertisols y Entisols desarrolla una estructura heterogénea conformada por agregados granulares y poros de empaquetamiento compuesto generados por la actividad biológica (Six et al., 2004). Sin la presencia de raíces como en Inceptisols, el suelo es más homogéneo y únicamente ocurren fisuras y bloques subangulares en donde sólo dominan los procesos físicos de humedecimiento y secado característicos de suelos arcillosos (Coulombe et al., 1996).

\section{Conclusiones}

La cuantificación de la porosidad del suelo a través de imágenes aisladas resulta ser un método confiable con una sobrestimación $<10 \%$, si el objetivo de la investigación es descriptivo y no pretende relacionar con otros componentes del suelo. Sin embargo, en agregados (tamaño y tipo) no se recomiendan pues el número de imágenes necesarias para obtener cuantificaciones estadísticamente representativas es variable y muy alto. 


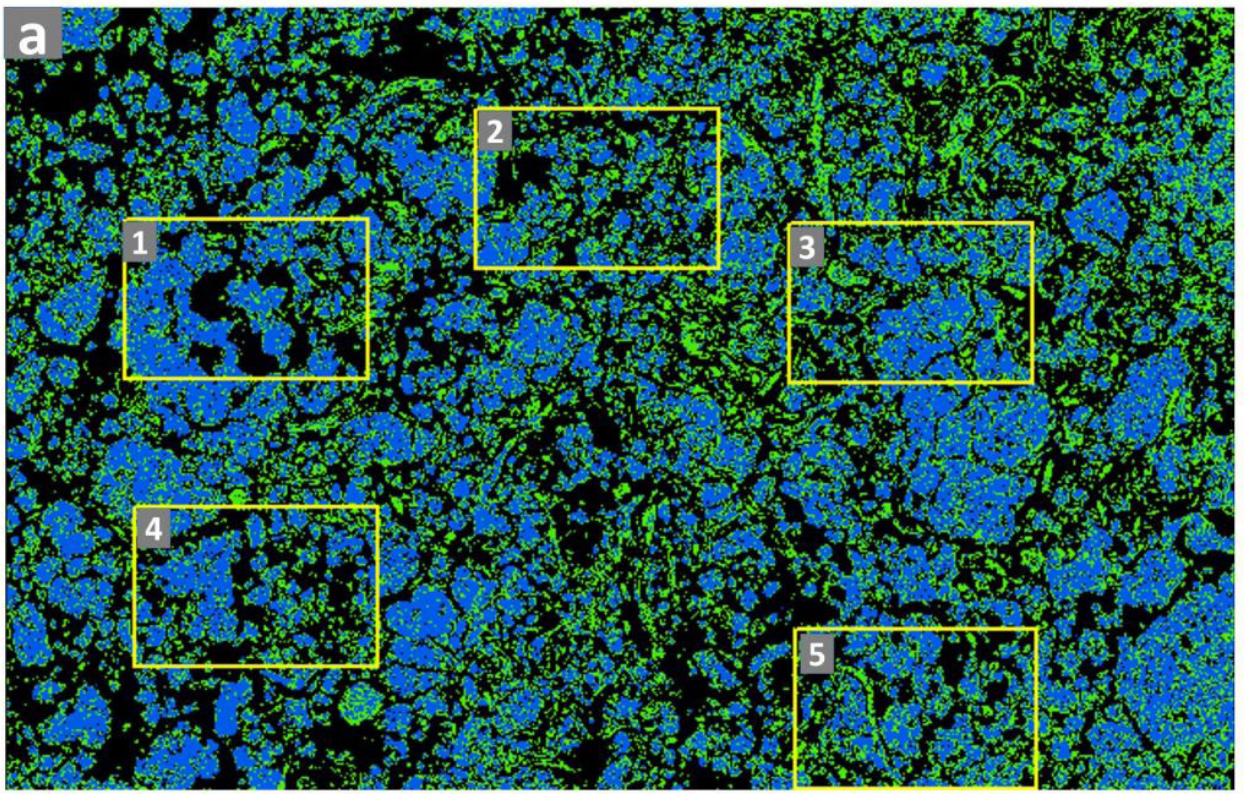

$A=34.44 \% \quad R=24.63 \quad P=40.98 \%$

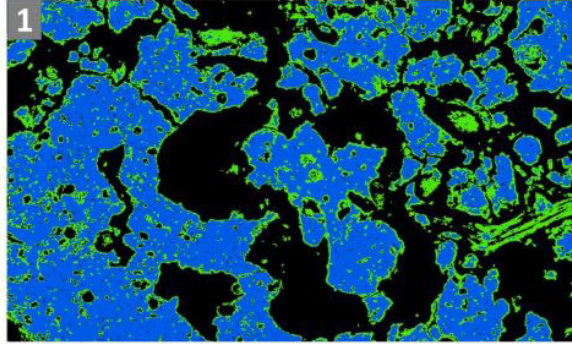

$A=40.05 \% \quad R=18.69 \quad P=41.25 \%$

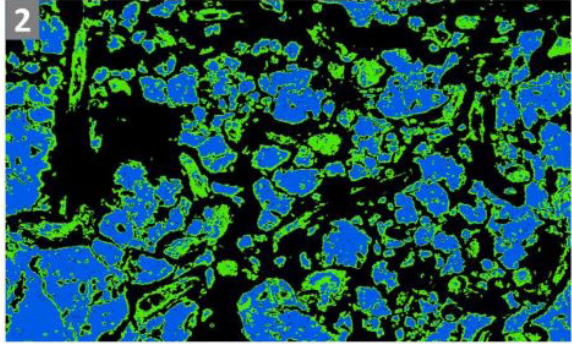

$A=32.04 \% \quad R=30.70 \quad P=37.24 \%$

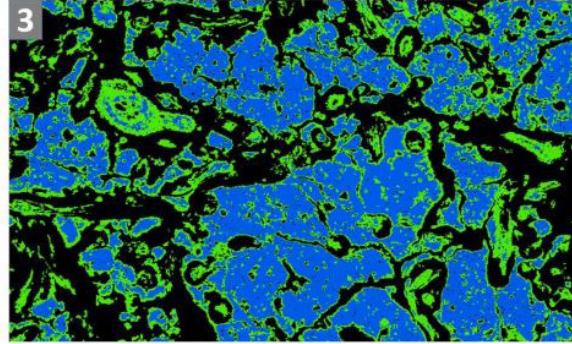

$A=40.05 \% \quad R=32.04 \quad P=27.90 \%$

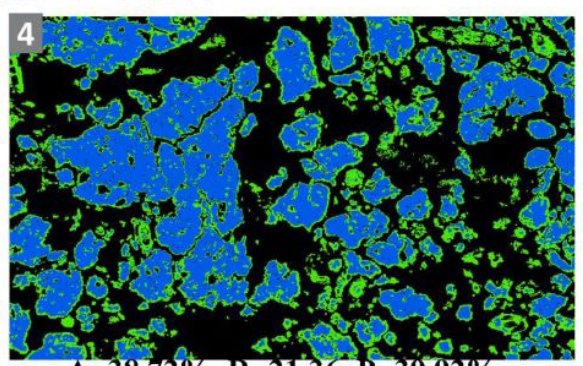

$\mathrm{A}=38.72 \% \quad \mathrm{R}=21.36 \quad \mathrm{P}=39.92 \%$

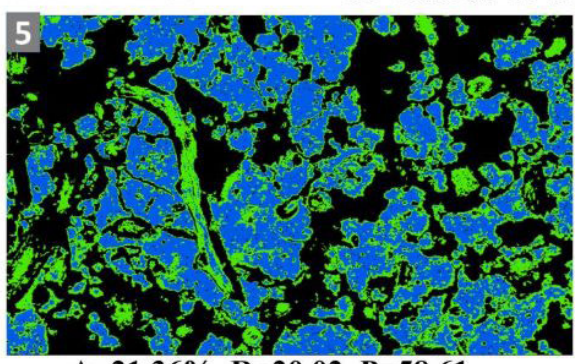

$A=\mathbf{2 1 . 3 6} \% \quad R=20.02 \quad P=58.61$

Raíces (R)

Agregados (A)

Espacio poroso (P)

Figura 6 Distribución de agregados, poros y raíces en un mosaico de alta resolución (a) y cinco imágenes aisladas en el tratamiento con mayor cantidad de raíces en Vertisols. Longitud del mosaico (a) $54.17 \mathrm{~mm}$ y de las fotografías aisladas (1 a 5) $8.32 \mathrm{~mm}$. 


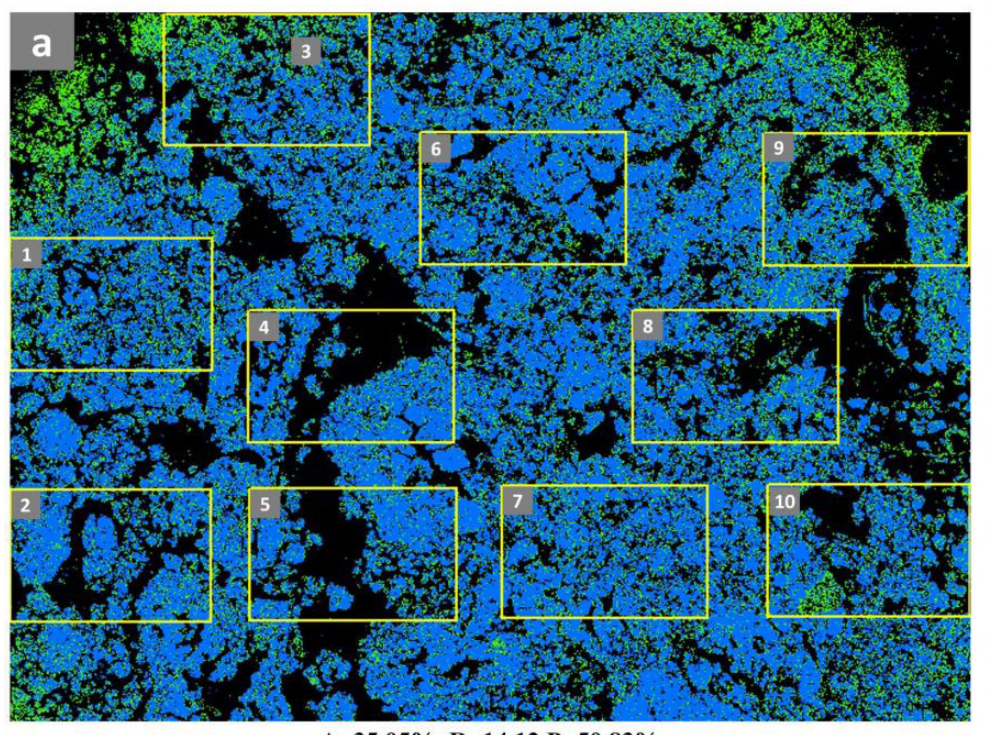

$\mathrm{A}=\mathbf{3 5 . 0 5} \% \mathrm{R}=\mathbf{1 4 . 1 2} \mathrm{P}=\mathbf{5 0 . 8 3} \%$
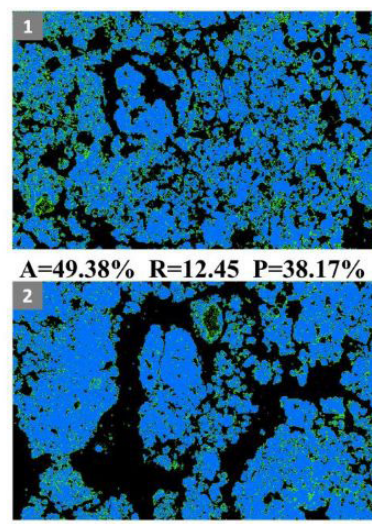

$A=31.08 \% \quad R=12.16 \quad P=56.76 \%$
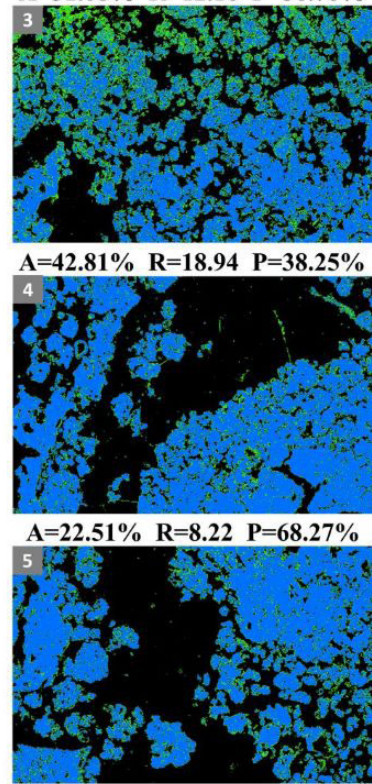

$A=40.02 \% \quad R=5.28 \quad P=54.70 \%$

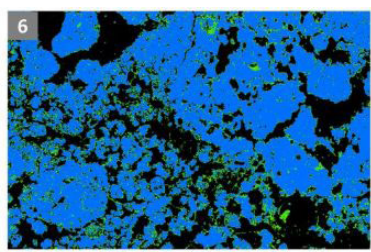

$A=50.56 \% \quad R=10.52 \quad P=40.92 \%$

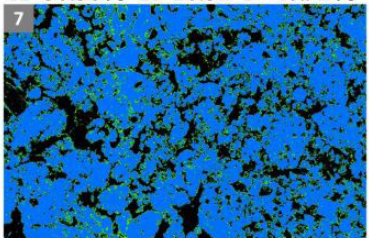

$A=63.42 \% \quad R=10.03 \quad P=26.55 \%$
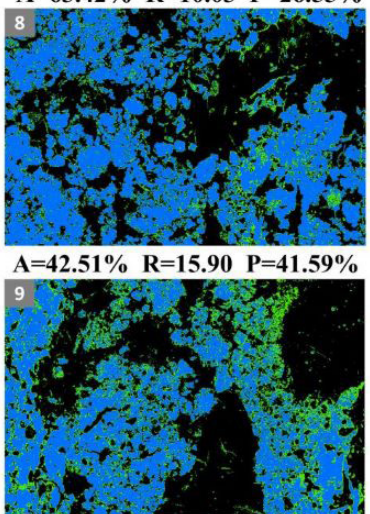

$A=35.71 \% \quad R=19.05 \quad P=45.24 \%$

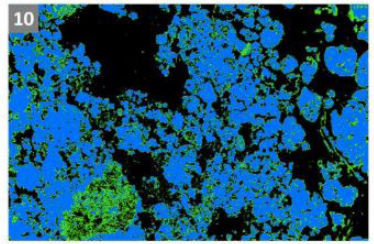

$A=39.32 \% \quad R=13.93 \quad P=46.75 \%$

Figura 7 Distribución de agregados, poros y raíces en un mosaico de alta resolución (a) y cinco imágenes aisladas en el tratamiento con mayor cantidad de raíces en Vertisols. Longitud del mosaico (a) $54.17 \mathrm{~mm}$ y de las fotografías aisladas (1 a 5 ) $8.32 \mathrm{~mm}$.

Tabla 5. Tiempo para realizar la delimitación y cuantificación de componentes del suelo en una sección delgada.

\begin{tabular}{|c|c|c|c|}
\hline \multicolumn{4}{|c|}{ Tiempo (minutos) } \\
\hline \multicolumn{4}{|c|}{ Fotografías aisladas } \\
\hline 3 & $\mathbf{5}$ & $\mathbf{1 0}$ & $\mathbf{4 9}$ \\
\hline 8 & 10 & 15 & 35 \\
\hline $\mathrm{ns}$ & $\mathrm{ns}$ & $\mathrm{ns}$ & 30 \\
\hline 5 & 10 & 15 & 15 \\
\hline 15 & 20 & 30 & 90 \\
\hline 28 & 40 & 60 & $170^{*}$ \\
\hline
\end{tabular}

Tiempo Total

Toma de fotografías

Unión de fotografías (mosaico)

Pretratamiento de imágenes

Análisis (segmentación, clasificación y cuantificación)

* El tiempo total comprende los vectores de cada componente del suelo a los cuales se les puede practicar cualquier análisis de medición espacial incluido en el software $\operatorname{ArcGis}^{\circledR,}$ (ns) no se requiere. 
Con los mosaicos de alta resolución es posible cuantificar y observar el patrón de distribución de los poros, agregados y raíces y sus inter-relaciones presentes en las secciones delgadas. Además, los diferentes componentes del suelo pueden ser categorizados según su diámetro, área o longitud, permitiendo generar estimaciones y generalizaciones con mayor certeza estadística al realizar repeticiones de secciones delgadas subsecuentes de un mismo bloque. En ese sentido, esta metodología ofrece cuantificaciones totales que pueden abarcar áreas en donde se desee monitorear los diferentes procesos y transformaciones del suelo.

\section{Referencias}

Adderley, W.P., Simpson, I.A., Davidson, D.A., 2002, Colour description and quantification in mosaic images of soil thin sections: Geoderma, 108(3-4), 181-195. https://doi. org/10.1016/s0016-7061(02)00123-4

Allen, D.E., Singh, B.P., Dalal, R.G., 2011, Soil health Indicators under climate change: A review of current knowledge, in Singh, B.P., Cowie, A.L., Yin Chan, A. (eds.), Soil Health and Climate Change: New York, Springer, 29, 25-49. https://doi. org/10.1007/978-3-642-20256-8_2

Aydemir, S., Keskin, S., Drees, L.R., 2004, Quantification of soil features using digital image processing (DIP) techniques: Geoderma, 119(1-2), 1-8. https://doi. org/10.1016/s0016-7061(03)00218-0

Bravo-Garza, M.R., Bryan, R.B., 2005, Soil properties along cultivation and fallow time sequences on Vertisols in Northeastern Mexico: Soil Science Society of America Journal, 69(2), 473-481. https://doi. org/10.2136/sssaj2005.0473

Bryk, M., 2016, Macrostructure of diagnostic $\mathrm{B}$ horizons relative to underlying $\mathrm{BC}$ and C horizons in Podzols, Luvisol, Cambisol, and Arenosol evaluated by image analysis: Geoderma, 263， 86-103. https://doi. org/10.1016/j.geoderma.2015.09.014
Bullock, P., Murphy, G.P., 1980, Towards the quantification of soil structure: Journal of Microscopy, 120(3), 317-328. https://doi. org/10.1111/j.1365-2818.1980.tb04151.x

Bullock, P., Fedoroff, N., Jongerius, A., Stoops, G., Tursina, T., Babel, U., 1985, Handbook for Soil Thin Section Description: Wolverhampton, UK, Waine Research Publications, 605 p.

Campbell,J., 1996, Introduction to remote sensing: New York, The Guilford Press, 287 p.

Carducci, G.E., Zinn, Y.L., Rossoni, D.F., Heck, R.J., Oliveira, G.C., 2017, Visual analysis and $\mathrm{X}$-ray computed tomography for assessing the spatial variability of soil structure in a cultivated Oxisol: Soil and Tillage Research, 173, 15-23. https://doi.org/10.1016/j. still.2016.03.006

Chesworth, W., 2008, Encyclopedia of the Earth Sciences: Dordrecht, The Netherlands, Springer, $189 \mathrm{p}$.

Coulombe, C.E., Wilding, L.P., Dixon, J.B., 1996, Overview of Vertisols: characteristics and impacts on society: Advances in Agronomy, 57, 289-375. https://doi.org/10.1016/ s0065-2113(08)60927-x

De León-González, F., Gutiérrez-Castorena, M.C., González-Chávez, M.C.A., CastilloJuárez, H., 2007, Root-aggregation in a pumiceous sandy soil: Geoderma, 142(34), 308-317. https://doi.org/10.1016/j. geoderma.2007.08.023

Environmental Systems Research Institute, 2015, ArcGis 10.3. Computer Software: Environmental Systems Research Institute Inc, Redlands, CA.

Fitzpatrick, E.A, 1984, Micromorphology of soils: New York, Champman and Hall, 427 p.

Fitzpatrick, E.A, 1990, Roots in the thin sections of soils: Development in Soil Science, 19, 9-23. https://doi.org/10.1016/ S0166-2481(08)70311-8

Gabioud, A.E., Wilson, M.G., Sasal, M.C., 2011, Análisis de la estabilidad de agregados por el método de Le Bissonnais en tres órdenes de suelos: Ciencia del Suelo, 29(2), 129-139. 
González, A.L., 2008, Elaboración de un mapa de suelos y evaluación de su calidad en el Colegio de Postgraduados campus Montecillo, Estado de México: México-España, Universidad de Lleida y Universidad Autónoma Chapingo, proyecto final de carrera. $125 \mathrm{p}$.

Gutiérrez, G.V.R., Mejía, C.J.M., 2015, Caracterización de propiedades físicas de suelos mediante análisis de imágenes y simulación fluido-dinámica a escala de poro, en Loaiza, J.C., Stoops, G., Poch, R.M., Casamitjana, M. (eds.), Manual de micromorfología de suelos y técnicas complementarias: Colombia, Fondo Editorial Pascual Bravo, 353-383.

Gutiérrez-Castorena, E.V., Gutiérrez-Castorena, M.C., Vargas, T.G., Bontemps, L.C., Martínez, J.D., Méndez, E.S., Solorio-Ortíz, C.A., 2016, Micromapping of microbial hotspots and biofilms from different crops using digital image mosaics of soil thin sections: Geoderma, 279, 11-21. https:// doi.org/10.1016/j.geoderma.2016.05.017

Gutiérrez-Castorena, M.C., Gutiérrez-Castorena, E.V., Gonzalez-Vargas, T., Solorio-Ortiz, C.A., Suástegui-Méndez, E.S., CajusteBontemps, L., Rodríguez-Mendoza, M.N., 2018, Thematic micro-maps of soil components using high-resolution mosaics from whole soil thin sections and image analysis: European Journal of Soil Science, 69(2), 217-231. https://doi.org/10.1111/ ejss. 12506

Jangorzo, N.S., Schwartz, C., Watteau, F., 2013, Image analysis of soil thin sections for a nondestructive quantification of aggregation in the early stages of pedogenesis: European Journal of Soil Science, 65(4), 485-498. https://doi.org/10.1111/ejss.12110

Kodešová, R., Kodeš, V., Žigová, A., Šimůnek, J., 2006, Impact of plant roots and soil organisms on soil micromorphology and hydraulic properties: Biologia, 61(19), 339-343. https://doi.org/10.2478/ s1 1756-006-0185-7
Kumi, F., Hanping, M., Jianping, H.M., Ullah, I., 2015, Review of applying X-ray computed tomography for imaging soil-root physical and biological processes: International Journal of Agricultural and Biological Engineering, 8 (5), 1-13. https://doi.org/10.3965/j. ijabe.20150805.1490

Lebedeva, M.P., Golovanov, D.L., Shishkov, V.A., Abrosimov, K.N., 2019, Microscopic and Tomographic Studies for Interpreting the Genesis of Desert Varnish and the Vesicular Horizon of Desert Soils in Mongolia and the USA: Boletín de la Sociedad Geológica Mexicana, 71(1), 21-42. https://doi. org/10.18268/bsgm2019v7 ln la3

Leonard, D., Sedov, S., Solleiro-Rebolledo, E., Fedick, S.L., Diaz, J., 2019, Ancient Maya Use of Hidden Soilscapes in the Yalahau Wetlands, Northern Quintana Roo, Mexico: Boletín de la Sociedad Geológica Mexicana, 71(1), 93-119. https://doi.org/10.18268/ bsgm2019v7 ln1a6

Marcelino, V., Cnudde, V., Vansteelandt, S., Carò, F., 2007, An evaluation of 2D-image analysis techniques for measuring soil microporosity: European Journal of Soil Science, 58(1), 133-140. https://doi. org/10.1111/j.1365-2389.2006.00819.x

Moran, C.J., 1993, Image processing and soil micromorphology: Developments in Soil Science, 22, 459-482. https://doi. org/10.1016/S0166-2481(08)70434-3

Moran, C.J., Pierret, A., Stevenson, A.W., 2000, $\mathrm{X}$-ray absorption and phase contrast imaging to study the interplay between plant roots and soil structure: Plant and Soil, 223, 99-115. https://doi.org/10.1023/A:1004835813094

Murphy, C.P., 1983, Point counting pores and illuvial clay in thin section: Geoderma, 31(2), 133-150. https://doi. org/10.1016/0016-7061(83)90004-6

Murphy, C.P., 1986, Thin Section Preparation of Soils and Sediments: Berkhamsted, UK, AB Academic, 149 p. 
Nunan, N., Wu, K., Young, I.M., Crawford, J.W., Ritz, K., 2003, Spatial distribution of bacterial communities and their relationships with the micro-architecture of soil: FEMS Microbiology Ecology, 44(2), 203-215. https://doi.org/10.1016/ s0168-6496(03)00027-8

Pagliai, M., Vignozzi, N., 2002, Image Analysis and Microscopic Techniques to Characterize Soil Pore System, in Blahovec, J., Kutílek, M. (eds.), Physical Methods in Agriculture: Boston, MA, Springer, 2-13.

Pineda-Marín, L., Gutiérrez-Castorena, M.C., Anicua-Sánchez, R., Cajuste-Bontemps, L., Gutiérrez-Castorena, E.V., 2012, Quantification of porosity in substrates using thin Sections and image analysis: Acta Horticulturae, 947, 105-110. https://doi. org/10.17660/actahortic.2012.947.11

Pires, L.F., Cassaro, F.A.M., Bacchi, O.O.S., Reichardt, K., 2011, Non-destructive image analysis of soil surface porosity and bulk density dynamics: Radiation Physics and Chemistry, 80(4), 561-566. https://doi. org/10.1016/j.radphyschem.2010.12.006

Poch, R.M., 2015, Micromorfometría, en Loaiza, J.C., Stoops, G., Poch, R.M., Casamitjana, M. (eds.), Manual de micromorfología de suelos y técnicas complementarias: Colombia, Fondo Editorial Pascual Bravo, 309-320.

Poch, R.M., Pascual, M., Villar, J., Rufat, J., 2019, Soil porosity changes in orchards with subsurface irrigation: quantification and interpretation: Boletín de la Sociedad Geológica Mexicana, 71(1), 1-10. https:// doi.org/10.18268/bsgm2019v7lnlal

Protz, R., VandenBygaart, A., 1998, Towards systematic image analysis in the study of soil micromorphology: Sciences of Soils, 3(1), 34-44. https://doi.org/10.1007/ s10112-998-0004-0

Protz, R., Sweeney, S.J., Fox, G.A., 1992, An application of spectral image analysis to soil micromorphology, 1. Methods of analysis: Geoderma, 53(3-4), 275-287. https://doi. org/10.1016/0016-7061(92)90059-g
Reynolds, W.D., Drury, G.F., Tan, G.S., Fox, C.A., Yang, X.M., 2009, Use of indicators and pore volume-function characteristics to quantify soil physical quality: Geoderma, 152(34), 252-263. https://doi.org/10.1016/j. geoderma.2009.06.009

Ringrose Voase, A.J., 1996, Measurement of soil macropore geometry by image analysis of sections through impregnated soil: Plant and Soil, 183(1), 27-47. https://doi. org/10.1007/bf02185563

Sauzet, O., Cammas, C., Marc, J., Bajard, M., Montagne, D., 2017, Development of a novel image analysis procedure to quantify biological porosity and illuvial clay in large soil thin sections: Geoderma, 292, 135-148. https://doi.org/10.1016/j. geoderma.2017.01.004

Schindelin, J., Arganda-Carreras, I., Frise, E., Kaynig, V., Longair, M., Pietzsch, T., Preibisch, S., Rueden, C., Saalfeld, S., Schmid, B., Tinevez, J., White, D.J., Hartenstein, V., Eliceiri, K., Tomancak, P., Cardona, A., 2012, Fiji: An open source platform for biological-image analysis: Nature Methods, 9(7), 676-682. https://doi. org/10.1038/nmeth.2019

Shipitalo, M.J., Protz, R., 1987, Comparison of morphology and porosity of a soil under conventional and zero tillage: Canadian Journal of Soil Science, 67(3), 445-456. https://doi.org/10.4141/cjss87-043

Six, J., Bossuyt, H., Degryze, S., Denef, K., 2004, A history of research on the link between (micro) aggregates, soil biota, and soil organic matter dynamics: Soil \& Tillage Research, 79(1), 7-31. https://doi.org/10.1016/j. still.2004.03.008

Stoops, G., 2003, Guidelines for Analysis and Description of Soil and Regolith Thin Sections: Madison, Wisconsin, USA, Soil Science Society of America, 184 p. https:// doi.org/10.2136/2003.guidelinesforanalysis 
Stoops, G., 2015, Composición de la masa basal y de los edaforrasgos, en Loaiza, J.C., Stoops, G., Poch, R.M., Casamitjana, M. (eds), Manual de micromorfología de suelos y técnicas complementarias: Colombia, Fondo Editorial Pascual Bravo, 309-320.

Stoops, G., 2018, Micromorphology as a Tool in Soil and Regolith Studies, in Stoops, G., Marcelino, V., Mees, F. (eds.), Interpretation of Micromorphological Features of Soils and Regoliths. Second edition: Netherlands, Elsevier, 1-21.

Taina, I.A., Heck, R.J., Elliot, T.R., 2008, Application of X-ray computed tomography to soil science: A literature review: Canadian Journal of Soil Science, 88(1), 1-19. https:// doi.org/10.4141/cjss06027

Terribile, F., FitzPatrick, E.A., 1992, The application of multilayer digital image processing techniques to the description of soil thin sections: Geoderma, 55(1-2), 159-174. https://doi. org/10.1016/0016-7061(92)90011-u

Torres-Guerrero, G.A., Gutiérrez-Castorena, M.C., Ortiz-Solorio, C.A., Herrera, J.M., Gutiérrez-Castorena, E.V., Etchevers, B.J.D., 2016, Effect of root decomposition on the soil structure using micromapping. Poster. 15th International Conference on Soil Micromorphology. Instituto de Geología UNAM. Mexico City.

Torres-Guerrero, G. A., M.C. GutiérrezCastorena, J.M. Herrera, C.A. OrtízSolorio y E.V. Gutiérrez-Castorena, 2019, Descomposición de las raíces de maíz a nivel de parcela y regional usando el conocimiento local de tierras y técnico de suelos: Agrociencia. 53(5), 661-680.
Totsche, K.U., Amelung, W., Gerzabek, M.H., Guggenberger, G., Klumpp, E., Knief, C., Lehndorff, E., Mikutta, R., Peth, S., Prechtel, A., Ray, N., Kögel-Knabner, I., 2017, Microaggregates in soils: Journal of Plant Nutrition \& Soil Science, 181(1), 1-33. https://doi.org/10.1002/jpln.201600451

Turk, J.K., Graham, R.C., 2014, A proposed master $\mathrm{V}$ horizon for the designation of near-surface horizons with vesicular porosity: Soil Science Society of America Journal, 78, 868-880.

VandenBygaart, A.J., Protz, R., 1999, The representative elementary area (REA) in studies of quantitative soil micromorphology: Geoderma, 89(3-4), 333-346. https://doi. org/10.1016/s0016-7061(98)00089-5

Watteau, F., Jangorzo, N.S., Schwartz, C.H., 2019, A micromorphological analysis for quantifying structure descriptors in a young constructed Technosol: Boletín de la Sociedad Geológica Mexicana, 71(1), 11-20. https:// doi.org/10.18268/bsgm2019v71nla2

Zaiets, O., Poch, R.M., 2016, Micromorphology of organic matter and humus in Mediterranean mountain soils: Geoderma, 272, 83-92. https://doi.org/10.1016/j. geoderma.2016.03.006 